\title{
Antibacterial Activity of Sucralfate versus Aluminum Chloride in Simulated Gastric Fluid
}

\author{
L. Welage ${ }^{1,2 *}$, P. Carver ${ }^{1,2}$, K. Welch ${ }^{3,4}$
}

\begin{abstract}
Studies have previously demonstrated that sucralfate possesses intrinsic antibacterial activity. This study was designed to indirectly assess whether aluminum is the active antibacterial component of sucralfate and to further evaluate factors that may influence this agent's antibacterial activity. Utilizing an in vitro model, the antibacterial activity of sucralfate, an equivalent quantity of aluminum in the form of aluminum chloride, and a control were compared. In addition, the influences of bacterial species (Enterobacter cloacae and Pseudomonas aeruginosa), time (0-24 h) and environmental pH $(3,5,7)$ on the agents' antibacterial activities were evaluated. Equivalent quantities of aluminum, as either sucralfate or aluminum chloride, were added to two of three flasks containing approximately $10^{5} \mathrm{cfu} / \mathrm{ml}$ of bacteria in $\mathrm{pH}$-adjusted simulated gastric fluid. The third flask served as a control. Samples were obtained over $24 \mathrm{~h}$, diluted and subcultured onto agar plates. The experiments demonstrated that bacterial growth was influenced by $\mathrm{pH}$, time and treatment (aluminum chloride or sucralfate). Regardless of pH or bacterial species, bacterial death occurred within 20 min following the addition of aluminum chloride. In contrast, bacterial death following the addition of sucralfate was more variable and appeared to be $\mathrm{pH}$ dependent. In conclusion, sucralfate and aluminum chloride both possess antibacterial activity, even at $\mathrm{pH}$ values that normally support bacterial growth in gastric fluid. Although differences in the antibacterial activity of the two agents may in part be related to drug-induced changes in $\mathrm{pH}$, these differences also support data suggesting that aluminum release from sucralfate is incomplete and is dependent on $\mathrm{pH}$.
\end{abstract}

Nosocomial pneumonia is an important cause of morbidity and mortality in critically ill patients. Overall, bacterial pneumonia is the most common cause of infection-related death, with mortality rates as high as $50 \%(1,2)$. Several investigators have postulated that increases in gastric $\mathrm{pH}$ lead to gastric bacterial colonization, which may in turn serve as a reservoir for bronchopulmonary infections (3-11). Although this view remains somewhat controversial (3-14), several studies have demonstrated that patients receiving sucralfate therapy, which does not significantly alter gastric $\mathrm{pH}$, have a lower incidence of pneumonia compared to patients receiving antacids or H2 receptor antagonists $(4,7,9)$. The lower risk of pneumonia may, in part, be related sucralfate's

\footnotetext{
${ }^{1}$ College of Pharmacy, ${ }^{2}$ Department of Pharmacy, University of Michigan Medical Center, ${ }^{3}$ Center for Statistical Consultation and Research, and ${ }^{4}$ School of Public Health, University of Michigan, 428 Church Street, Ann Arbor, Michigan 48109 1065, USA.
}

ability to maintain the normal gastric acid bactericidal barrier. However, studies have also shown that the incidence of gastric bacterial colonization and subsequent pneumonia during sucralfate therapy remains low despite many patients having gastric $\mathrm{pH}$ values of $>4.0(4,7,9)$. Thus, sucralfate appears to possess some intrinsic antibacterial activity. This hypothesis has been confirmed in vitro; sucralfate demonstrates marked antibacterial activity against Escherichia coli, Klebsiella pneumoniae, Staphylococcus aureus and Pseudomonas aeruginosa (15-17).

Although it is recognized that sucralfate, a basic aluminum salt of sucrose octasulfate, possesses antibacterial properties, the active component of sucralfate has not yet been identified. Since it is well recognized that many metals, including mercury and bismuth, have antibacterial activity, we postulated that the aluminum component of sucralfate may be the active moiety responsible for its antibacterial activity $(18,19)$. Since aluminum release from sucralfate is $\mathrm{pH}$ dependent, 
we further hypothesized that sucralfate's antibacterial activity would be influenced by the $\mathrm{pH}$ of the gastric fluid $(20,21)$. This comparative study was performed to characterize the influence of $\mathrm{pH}$ and bacterial species on sucralfate's antibacterial activity and to ascertain whether aluminum possesses antibacterial activity. Specifically, this study was designed to compare the antibacterial activity of sucralfate, an equivalent amount of aluminum in the form of aluminum chloride and control against two common gramnegative pathogens. Since $\mathrm{pH}$ and time may influence bacterial growth, antibacterial activity and aluminum release from the agents, serial experiments were conducted in simulated gastric fluid at $\mathrm{pH}$ values 3,5 and 7 over a $24 \mathrm{~h}$ study period.

\section{Materials and Methods}

In order to simulate clinical conditions, $1 \mathrm{~g}$ sucralfate tablets (Carafate, lot no. S8460, Marion Laboratories, USA) and an equivalent amount of aluminum $(206.9 \mathrm{mg})$ in the form of $1.022 \mathrm{~g}$ aluminum chloride (EM Industries, USA) were used in all experiments. Simulated gastric fluid was prepared according to the United States Pharmacopeia formulation (USP XXI-NF XVI; U.S. Pharmacopocial Convention, Rockville, MD, 1985) and adjusted to the desired $\mathrm{pH}(3,5$ or 7$)$ just prior to each experiment by the addition of aqueous $1.0 \mathrm{M}$ or $2.0 \mathrm{M}$ sodium hydroxide (lot no. 7689 KELM, Mallinckrodt, USA) or hydrochloric acid (lot no. $3560 \mathrm{KBBK}$, Matlinckrodt) (22). The $\mathrm{pH}$ was measured using a $\mathrm{pH}$ meter (Orion Research Digital Ionalyzer/501) calibrated to $\mathrm{pH} 4$ and $\mathrm{pH} 7$ with standardized phosphate buffer solutions (VWR Scientific, USA).

Pseudomonas aeruginosa (ATCC 27853) and Enterobacter cloacae (ATCC 13047) were obtained from the American Type Culture Collection (Rockville, MD). These organisms were selected as the test otganisms because they are frequently implicated as pathogens in nosocomial pneumonia and are often difficult to eradicate. Bacterial cultures were prepared by inoculating $5 \mathrm{ml}$ of Mueller-Hinton broth (Difco Laboratories, USA) with $5 \mathrm{cfu}$ of bacteria from a stock plate and incubating the broth inoculum for 18 to $24 \mathrm{~h}$ at $37^{\circ} \mathrm{C}$. Overnight broth cultures containing approximately $10^{9} \mathrm{cfu} / \mathrm{ml}$ were serially diluted with Mueller-Hinton broth and plated on Mueller-Hinton agar (Difco Laboratories) to confirm the number of organisms present in the culture and to quantify the baseline inoculum used in each experiment.

Experimental Design. On each day of the experiments, $50 \mathrm{ml}$ of $\mathrm{pH}$-adjusted simulated gastric fluid and a magnetic stirring bar were added to three sterile Erlenmeyer flasks, which were subsequently inoculated with $0.5 \mathrm{ml}$ of the overnight culture of bacteria (Pseudomonas aeruginosa or Enterobacter cloacae) to produce a final bacterial concentration of approximately $10^{5} \mathrm{cfu} / \mathrm{ml}$. A time zero sample was obtained from each flask and serially diluted in Mueller-Hinton broth, and $0.1 \mathrm{ml} \mathrm{samples} \mathrm{of}$ the dilutions were cultured in duplicate on Mueller-Hinton agar plates. Subsequently, the flasks were treated with either $1 \mathrm{~g}$ sucralfate, $1.022 \mathrm{~g}$ aluminum chloride or no drug (control). Samples were obtained from each flask at $0.33,0.67,1,2,4,6,8,12$ and $24 \mathrm{~h}$ and serially diluted with Mueller-Hinton broth. $0.1 \mathrm{ml}$ samples of the dilutions were cultured in duplicate on Mueller-Hinton agar. Colony counts were determined by the spread plate technique, in which the sample was pipetted onto the surface of solidified Mueller-Hinton agar in a petri dish and the cells distributed with a wire. Bacterial colonies were manually quantified on each plate following overnight incubation at $37^{\circ} \mathrm{C}$. Experiments were performed in triplicate at each of the desired $\mathrm{pH}$ values $(3,5$ and 7$)$ with each of the test organisms.

Statistical Analyses. Initial bacterial inoculums for each of the experiments were compared using a two-way analysis of variance utilizing the Statistica software package (Statsoft, USA) (CCS:Statistica Volume I-III, Statsoft, USA, 1991). Percent reductions in $\log \mathrm{cfu} / \mathrm{ml}$ were determined based on the log cfu/ml prior to the addition of the agents (time zero) minus the log cfu/ml at each timepoint divided by $\log \mathrm{cfu} / \mathrm{ml}$ at time zero and multipled by 100 . Bacterial killing curves were constructed by plotting log bacterial $\mathrm{cfu} / \mathrm{ml}$ versus time for each of the conditions. The rates of kill for the two treatments (aluminum chloride and sucralfate) were determined from the slopes of the log bacterial concentration versus time profiles. Differences in killing rates between the two treatments were evaluated with a two-way analysis of variance. Other factors in the model included $\mathrm{pH}$ and bacterial species. Post hoc comparisons were performed using Tukeys contrast method. Significance was defined as a $p$ value of $\leq 0.05$. Data are represented as the mean \pm one standard deviation, unless otherwise stated.

Initially, comparisons in the log number of $\mathrm{cfu} / \mathrm{ml}$ for each treatment, $\mathrm{pH}$ and timepoint were to be made utilizing analysis of variance. However, since a critical assumption for the analysis of variance (i.e. equal variance among groups) could not be met, a Bayesian analysis was utilized (22). The probability that all of the $\mathrm{cfu} / \mathrm{ml}$ in a given treatment-pH combination would die before the end of the study period given the probability of dying for each treatment-pH combination was modelled. The Bayesian analysis used the distribution of the data from the experiment along with the prior probability of dying (assumed to be uniform for all treatment-pH combinations) to determine the posterior probability of dying (i.e. the updated probability of dying, given the observed data). The posterior distributions of the probability of dying were then compared for each treatment-pH combination to determine if there were any significant differences.

The posterior probability of dying in each cell of the study design is distributed as a beta distribution, with parameters $k-1$ and $n-k-1$, where $n$ is the total number of flasks in the cell and $k$ is the number of flasks in the cell in which all colonies died. The MIDAS (Michigan Interactive Data Analysis System) computer program was used to generate 10,000 cases of a simulated beta distribution that could be used to compare the probability of dying for the different treatment-pH combinations. This analysis permitted direct comparison of the probabilities that the given treatment-pH combinations would kill all of the colony-forming units within the $24 \mathrm{~h}$ study period. 


\section{Results}

The initial broth cultures used to inoculate the simulated gastric fluid contained $10^{8}$ to $10^{9} \mathrm{cfu} / \mathrm{ml}$. The mean log cfu/ml broth inoculums for Enterobacter cloacae were $9.39 \pm 0.44,9.36$ \pm 0.02 and $9.16 \pm 0.35$ for $\mathrm{pH}$ values 3,5 and 7 , respectively, and were not significantly different from one another. Similarly, the mean $\log \mathrm{cfu} / \mathrm{ml}$ broth inoculums for Pseudomonas aeruginosa were $9.42 \pm 0.03,9.39 \pm 0.16$, and $9.48 \pm 0.19$ for $\mathrm{pH}$ values 3,5 and 7 , respectively $(\mathrm{p}>0.05)$. Since baseline broth inoculums were not significantly different between the individual experiments, the inoculum was not used as a covariate in subsequent analyses.

As shown in Figure 1, bacterial growth for Enterobacter cloacae and Pseudomonas aeruginosa in the absence of sucralfate or aluminum chloride was significantly influenced by the $\mathrm{pH}$ of the environment. As anticipated, bacterial concentrations were significantly greater over time at the higher $\mathrm{pH}$ values. The addition of aluminum chloride or sucralfate resulted in dramatic bacterial killing. The organisms were significantly more likely to be dead at $24 \mathrm{~h}$ following the addition of aluminum chloride or sucralfate as compared to control. However, when the aluminum chloride and sucralfate treatments were compared by Bayesian methods, no significant differences were detected in the probability of all organisms dying within the $24 \mathrm{~h}$ study period. As shown in Figures 2 and 3, the addition of aluminum chloride resulted in rapid bacterial eradication that was independent of $\mathrm{pH}$ or organism. Death of all organisms occurred within $20 \mathrm{~min}$ following the addition of the aluminum chloride at all $\mathrm{pH}$ values studied. Conversely, following the addition of sucralfate, the rate of bacterial death was much slower and more variable and appeared to be influenced by $\mathrm{pH}$.

The mean rates of bacterial killing for Enterobacter cloacae were $0.39 \pm 0.14,1.2 \pm 0.72$ and 0.99 $\pm 0.77 \mathrm{~h}^{-1}$ at $\mathrm{pH} 3,5$ and 7 , respectively, following the addition of sucralfate and were significantly slower than those seen following the addition of aluminum chloride $(15.52 \pm 1.98,15.99 \pm 0.76$ and $15.80 \pm 1.89 \mathrm{~h}^{-1}$ at $\mathrm{pH} 3,5$ and 7 , respectively). Similarly, the mean rates of bacterial killing for Pseudomonas aeruginosa were $1.38 \pm 0.36,0.44$ \pm 0.06 and $0.44 \pm 0.09 \mathrm{~h}^{-1}$ following the addition of sucralfate as compared to $16.18 \pm 0.18,15.09$ \pm 1.69 and $16.43 \pm \mathrm{Oh}^{-1}$ at $\mathrm{pH} 3,5$ and 7 , respectively, following the addition of aluminum chloride $(\mathrm{p}<0.05)$. The mean rate of bacterial death was significantly different for the two treatment regimens (aluminum chloride versus sucralfate) but was not significantly influenced by bacterial species or $\mathrm{pH}$.

The addition of either sucralfate or aluminum chloride to simulated gastric fluid resulted in dramatic changes in the $\mathrm{pH}$ of the solutions. The addition of $1 \mathrm{~g}$ of sucralfate to $50 \mathrm{ml}$ of simulated gastric fluid with an initial $\mathrm{pH}$ of 3,5 or 7 resulted in solutions with $\mathrm{pH}$ values of $4.31,4.77$ and 5.07 , respectively. The addition of $1.022 \mathrm{~g}$ of aluminum chloride to $50 \mathrm{ml}$ of simulated gastric fluid with a

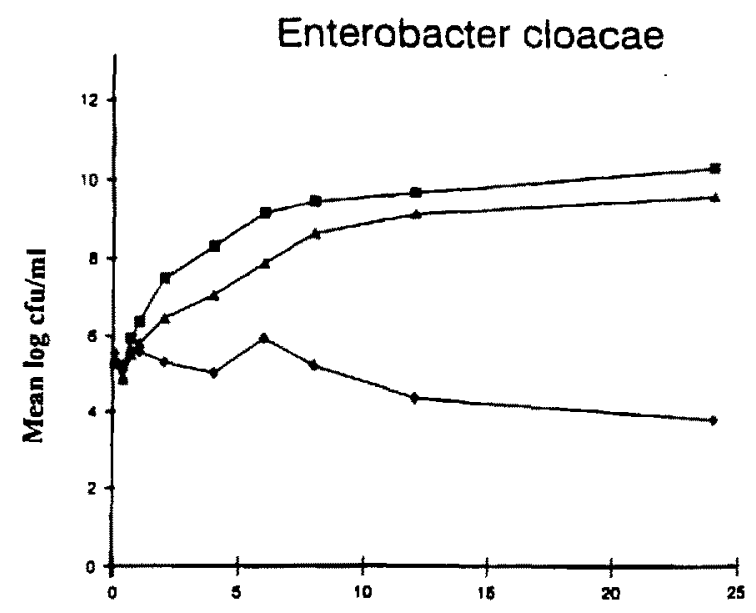

Figure 1a: Mean log bacterial cfu/ml over time for Enterobacter cloacae at $\mathrm{pH} 3(\bullet), 5(\boldsymbol{\Lambda})$ and $7(\mathbf{m})$ in the absence of aluminum chloride or sucralfate (control).

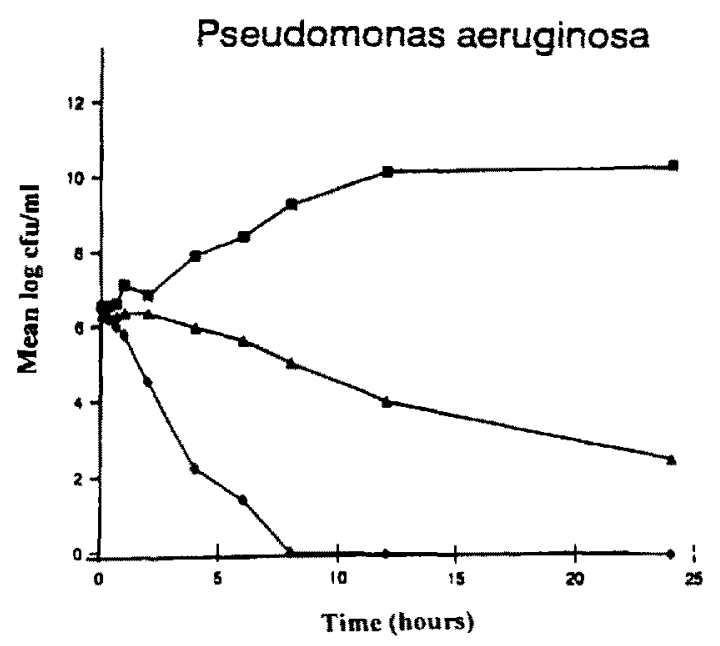

Figure 1b: Mean log bacterial cfu/ml over time for Pseudomonas aeruginosa at $\mathrm{pH} 3(\bullet), 5(\mathbf{\Delta})$ and $7(\boldsymbol{\square})$ in the absence of aluminum chloride or sucralfate (control). 
$\mathrm{pH}$ of 3,5 or 7 resulted in final $\mathrm{pH}$ values of the solutions of $3.31,3.27$ and 3.33 , respectively.

\section{Discussion}

This study demonstrates that both sucralfate and aluminum chloride possess marked antibacterial activity against Enterobacter cloacae and Pseudo.
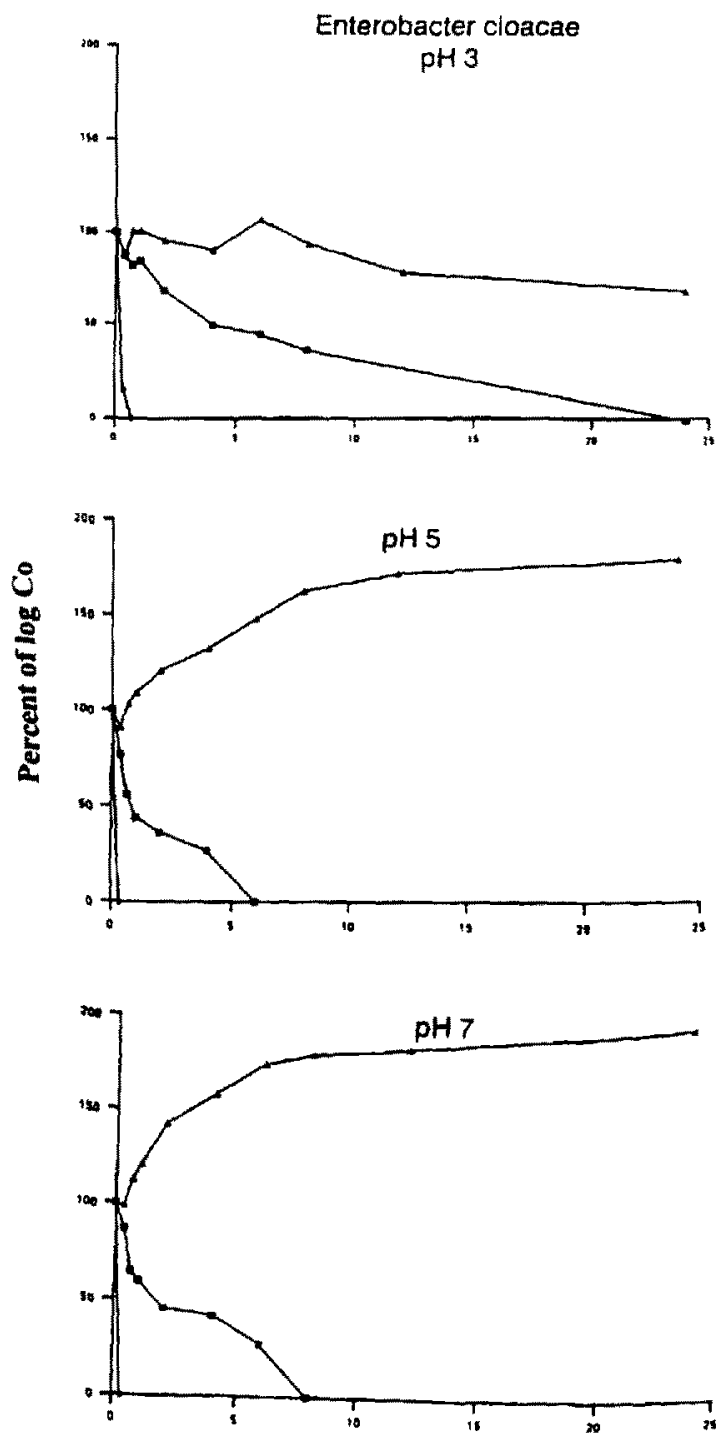

Time (hours)

Figure 2: Mean percent reduction in log $\mathrm{cfu} / \mathrm{ml}$ from baseline

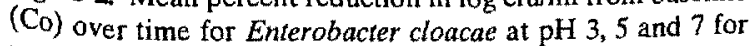
sucralfate ( $\mathbf{C}$ ), aluminum chloride $(\bullet)$ and no drug (control) (A). Co is the initial bacterial inoculum of the simulated gastric luid. monas aeruginosa. Sucralfate's antibacterial activity was variable and appeared to be $\mathrm{pH}$ dependent; however, this trend did not reach statistical significance. Conversely, bacterial death rates following the addition of aluminum chloride were rapid and, on superficial inspection, appeared to be independent of $\mathrm{pH}$. However, it is important to recognize that the $\mathrm{pH}$ of the solution following the addition of aluminum chloride was approximately 3.3, regardless of the initial $\mathrm{pH}$ (3, 5 or 7). Although pH changes were also observed
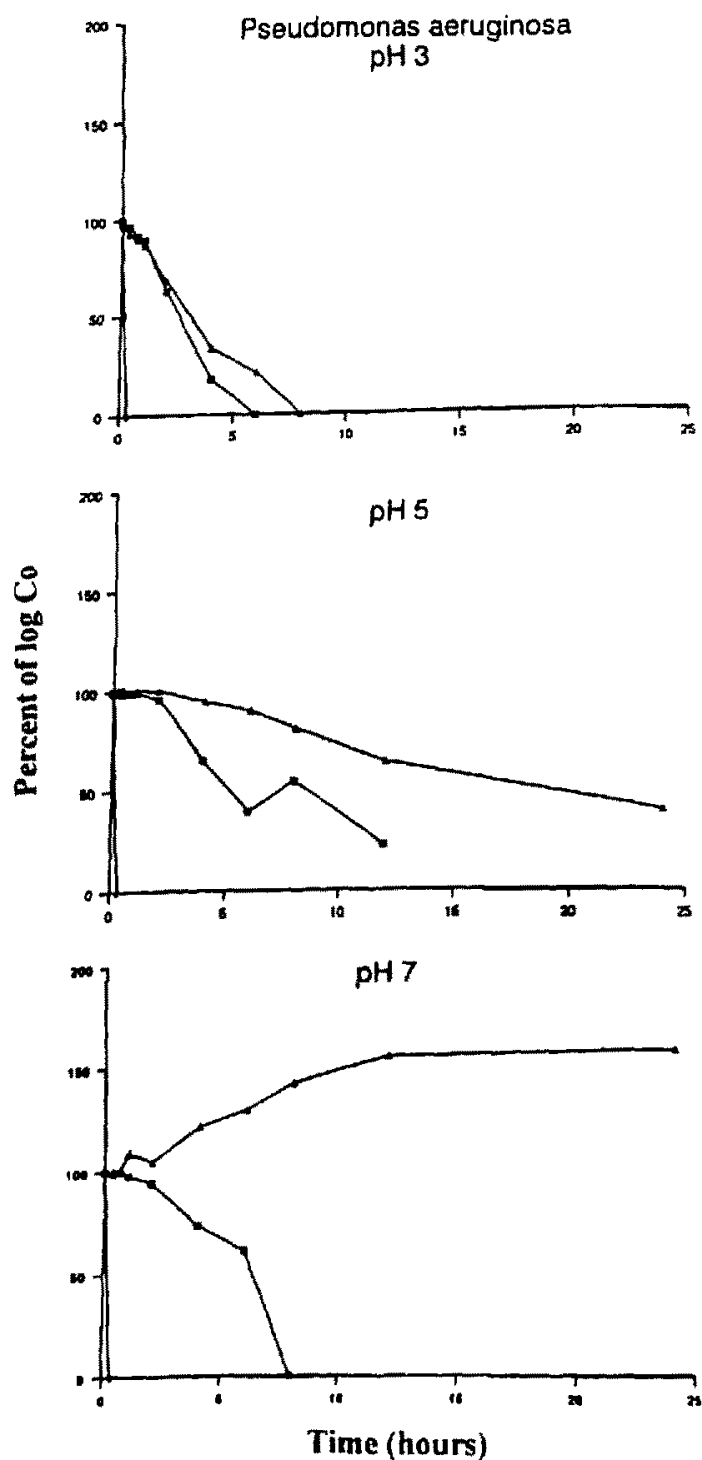

Figure 3: Mean percent reduction in $\log \mathrm{cfu} / \mathrm{ml}$ from baseline (Co) over time for Pseudomonas aeruginosa at $\mathrm{pH} \mathrm{3,5}$ and 7 for sucralfate (E), aluminum chioride ( $\bullet$ ) and no drug (control) (A). Co is the initial bacterial inoculum of the simulated gastric fluid. 
following the addition of sucralfate, these changes were less dramatic and were of a magnitude similar to those observed by other investigators (15-17). Since both agents influenced $\mathrm{pH}$, we cannot fully assess the influence of $\mathrm{pH}$ on the agents' antibacterial activities.

Previous studies utilizing a variety of methodologies have demonstrated that sucralfate possesses antibacterial activity against Klebsiella pneumoniae, Escherichia coli, Staphylococcus aureus and Pseudomonas aeruginosa (15-17). Data suggests that the degree of antibacterial activity is dependent upon the bacterial species; antibacterial activity against Pseudomonas aeruginosa is less than that against other gram-negative organisms (15-17). Our data demonstrates that sucralfate also possesses marked antibacterial activity against Enterobacter cloacae, a common respiratory pathogen in critically ill patients. At $\mathrm{pH}$ values 5 and 7, bacterial killing following the addition of sucralfate was more rapid for Enterobacter cloacae than for Pseudomonas aeruginosa. This finding further supports the concept that sucralfate's antibacterial activity against Pseudomonas aeruginosa is less than that against other gram-negative organisms.

Direct comparison of our results to those found in the literature is difficult due to the numerous methodologies employed $(15-17,23)$. For example, Goeger et al. (23) demonstrated bacterial growth of Pseudomonas aeruginosa, Escherichia coli and Staphylococcus aureus at $\mathrm{pH}$ values 3,4 and 6 in the presence of sucralfate. On the basis of these findings, the authors concluded that sucralfate promotes bacterial growth. These findings are in direct contradiction to our results as well as those of Tryba and Mantey-Stiers (15), Kappstein and Engels (16) and Daschner et al. (17). A potential explanation for these disparate results is the media used (15-17,23). Goeger et al. (23) utilized a bicarbonate solution that contained pepsin (with or without the addition of milk). Other investigators, including ourselves, have utilized simulated gastric fluid, which yields results similar to those observed by Tryba and Mantey-Stiers (15), who utilized human gastric fluid (15-17).

Two additional differences between our study design and others are the size of the bacterial inoculum and the concentration of sucralfate employed $(15-17,23)$. Our study utilized higher initial bacterial inoculums $\left(10^{5} \mathrm{cfu} / \mathrm{ml}\right)$ than have previously been reported. Although previous studies have assessed the antibacterial activity of solutions containing $1.5,2.5$ and $5 \%$ sucralfate, we chose to evaluate the activity of a $2 \%$ sucralfate solution $(1 \mathrm{~g} / 50 \mathrm{ml})(16,17,23)$. We intentionally chose to assess the antibacterial activity of a usual therapeutic dose of sucralfate $(1 \mathrm{~g})$ in a small fluid environment (i.e. $50 \mathrm{ml}$ of simulated gastric fluid). Despite using higher initial inoculums and a different concentration of sucralfate, we obtained results similar to those of Kappstein and Engels (16), who utilized a similar study design.

It has long been recognized that a variety of metal and organometallic compounds can inhibit the growth of bacteria, fungi and parasites. Although widespread clinical use of metals and organometallic compounds has been hampered by their toxic effects on humans and the development of resistant bacteria, recent studies have focused on the synthesis of less toxic agents with potent antibacterial activity (24). For example, dental prosthetic materials that contain silver, zinc, copper, fluoride and mercury have been shown to have antibacterial activity against a wide variety of oral flora (25). Similarly, the incorporation of silver into the polymer matrix of intravenous or urinary catheters is beneficial in decreasing the local concentrations of bacteria and may prove useful in decreasing the incidence of catheter-related infections (26). The antibacterial activity of bismuth has been studied both in vitro and in human subjects for the treatment of duodenal ulcers associated with Helicobacter pylori $(19,27)$.

Since sucralfate is a basic aluminum salt of sucrose octasulfate and metals are known to possess antibacterial activity, we hypothesized that aluminum was the active component responsible for sucralfate's antibacterial activity. In order to indirectly assess this, we evaluated the antibacterial activity of an equivalent quantity of aluminum (206.9 $\mathrm{mg}$ ) when administered as aluminum chloride. Aluminum chloride was chosen because it is soluble in aqueous media and should completely dissociate to aluminum plus hydrochloric acid (28). This agent would therefore allow assessment of the antibacterial activity of the maximum amount of aluminum $(206.9 \mathrm{mg}$ ) that could theoretically be released from sucralfate. On the basis of the $\mathrm{pH}$ changes observed following the addition of aluminum chloride, we strongly believe that aluminum completely dissociated from the agent. In addition, we believe that the antibacterial activity observed after the addition of aluminum chloride is the result of the free aluminum and not solely the result of the $\mathrm{pH}$ changes induced by the addition of the aluminum chloride. The addition of aluminum chloride re- 
sulted in a $\mathrm{pH}$ of approximately 3.3. However, bacterial death was far more rapid in the aluminum chloride solutions than in the control solutions at $\mathrm{pH} 3$.

It is also clear from our results that sucralfate's antibacterial activity is slower and more variable than that observed with aluminum chloride. We believe this reflects the fact that aluminum does not completely dissociate from sucralfate and therefore is not completely available to exert an antibacterial effect. Previous studies have shown that the release of aluminum from sucralfate is $\mathrm{pH}$ dependent, with a greater amount of aluminum being released at lower $\mathrm{pH}$ values (21). It is difficult to separate the influence of $\mathrm{pH}$ on aluminum release and subsequent bacterial death from the influence of $\mathrm{pH}$ alone on bacterial death. Theoretically, one could attempt to assess the antibacterial activity of the agents independent of $\mathrm{pH}$ by titrating the simulated gastric fluid to the initial $\mathrm{pH}$. However, this would not accurately reflect the clinical situation. In addition, titrating the simulated gastric fluid to the initial $\mathrm{pH}$ level may theoretically alter the amount of aluminum available.

Although our data demonstrate that aluminum chloride possesses marked antibacterial activity, this does not appear to be the case for other aluminum-containing products. Tryba and ManteyStiers (15) demonstrated that an antacid containing aluminum hydroxide, magnesium hydroxide and calcium carbonate did not have antibacterial activity against Escherichia coli and Pseudomonas aeruginosa. On the basis of their findings, one may conclude that aluminum does not possess antibacterial activity; however, we postulate that little or no aluminum is released from the insoluble antacid to subsequently be available to exert an antibacterial effect (28). Alternatively, the dose of antacid may not have been sufficient to provide antibacterial activity.

Our findings clearly demonstrate that both sucralfate and aluminum chloride possess marked antibacterial activity. Since we were unable to test the antibacterial activity of the sucrose octasulfate portion, we cannot directly conclude that aluminum is the active antibacterial component of sucralfate. However, the striking antibacterial activity observed with aluminum chloride demonstrates that aluminum possesses antibacterial activity. On the basis of these data, we infer that aluminum is the active antibacterial component of sucralfate. The antibacterial activity of sucralfate may be pH dependent, secondary to the in- fluence of $\mathrm{pH}$ on aluminum release as well as the influence of $\mathrm{pH}$ on bacterial growth. Although this hypothesis cannot be completely evaluated in our study due to sucralfate-induced alterations in $\mathrm{pH}$, it could be evaluated in future trials by measuring aluminum concentrations and correlating these concentrations with antibacterial activity. In summary, we suggest that aluminum is the active antibacterial moiety in sucralfate. Therefore, aluminum may be responsible for the lower incidence of gastric bacterial colonization and pneumonia observed in several clinical trials comparing sucralfate, antacids and $\mathrm{H} 2$ receptor antagonists $(4,7,9)$.

\section{Acknowledgements}

We gratefully acknowledge and thank Susan Kracke and Michael Carter for their assistance in the laboratory. In addition, we would like to thank John Warner for his assistance and guidance regarding the Bayesian statistical approach employed.

\section{References}

1. Statistical abstract of the United States. 104th edition. U.S. Government Printing Office, Washington DC, 1984.

2. Craven DE, Driks MR: Nosocomial pneumonia in the intubated patient. Seminars in Respiratory Infections 1987, 2: 20-33.

3. DuMoulin GC, Hedley-White J, Paterson DG, Lisbon A: Aspiration of gastric bacteria in antacid treated patients: a frequent cause of postoperative colonisation of the airway. Lancet 1982, i: 142.

4. Driks MR, Craven DE, Celli BR, Manning M, Burke RA, Garvin GM, Kunches M, Farber HW, Wedel SA, McCabe WR: Nosocomial pneumonia in intubated patients given sucralfate as compared with antacids or histamine type 2 blockers. New England Journal of Medicine 1987, 317: 1376-1382.

5. Inglis TJJ, Sproat LJ, Sherratt MJ, Hawkey PM, Gibson JS, Shah MV: Gastroduodenal dysfunction as a cause of gastric bacterial overgrowth in patients undergoing mechanical ventilation of the lungs. British Journal of Anaesthesia 1992, 8: 499-502.

6. Inglis TJJ, Sherratt MJ, Sproat LJ, Gibson JS, Hawkey PM: Gastroduodenal dysfunction and bacterial colonization of the ventilated lung. Lancet 1993, 341: 911-913.

7. Kappstein I, Schulgen G, Friedrich T, Hellinger P: Incidence of pneumonia in mechanically ventilated patients treated with sucralfate or cimetidine as prophylaxis for stress bleeding: bacterial colonization of the stomach. American Journal of Medicine 1991, 91, Supplement 2A: 125-131.

8. Garvey BM, McCambley JA, Tuxen DV: Effects of gastric alkalization on bacterial colonization in critically ill patients. Critical Care Medicine 1989, 17: 211-216.

9. Eddleston JM, Vohra A, Scott P, Tooth JA, Person RC, McCloy RF, Morton AK, Doran BH: A comparison of the frequency of stress ulceration and secondary pneumonia in sucralfate- or ranitidine-treated intensive care unit patients, Critical Care Medicine 1991, 19: 1491-1496. 
10. Tryba M: Side effects of stress bleeding prophylaxis. American Journal of Medicine 1989, 86, Supplement 6A: 85-93.

11. Tryba M: The gastropulmonary route of infection - fact or fiction? American Joumal of Medicine 1991, 91, Supplement 2A: 135-146.

12. Simms HH, DeMaria E, McDonald L, Peterson D, Robinson $A$, Burchard KW: Role of gastric colonization in the development of pneumonia in critically ill trauma patients: results of a prospective randomized trial. Journal of Trauma 1991, 31: 531-537.

13. Cook DJ, Laine LA, Guyatt GH, Rafrin TA: Nosocomial pneumonia and the role of gastric $\mathrm{pH}$ : a meta-analysis. Chest 1991, 100: 7-13.

14. Martin LF, Booth FV, Karlstadt RG, Silverstein JH, Jacobs DM, Hampsey J, Bowman SC, D'Ambrosio CA, Rockhold FW: Continuous intravenous cimetidine decreases stress-related upper gastrointestinal hemorrhage without promoting pneumonia. Critical Care Medicine 1993, 21: 19-30.

15. Tryba M, Mantey-Stiers F: Antibacterial activity of sucralfate in human gastric juice. American Journal of Medicine 1987, 83, Supplement 3B: 125-127.

16. Kappstein I, Engels I: Antibacterial activity of sucralfate and bismuth subsalicylate in simulated gastric fluid. European Journal of Clinical Microbiology and Infectious Diseases 1987; 6: 216-217.

17. Daschner F, Kappstein I, Engels I, Reuschenbach K, PFisterer $\mathbf{J}$, Krieg $\mathbf{N}$, Vogel $\mathbf{W}$ : Stress ulcer prophylaxis and ventilation pneumonia: prevention by antibacterial cytoprotective agents? Infection Control and Hospital Epidemiology 1988, 9: 59-65.

18. Foster TJ: Plasmid determined resistance to antimicrobial drugs and toxic metal ions in bacteria. Microbiological Reviews 1983, 47: 361-409.
19. Sox TE, Olson CA: Binding and killing of bacteria in bismuth subsalicylate. Antimicrobial Agents and Chemotherapy 1989, 33: 2075-2082.

20. Nagashima R: Development and characteristics of sucralfate. Journal of Clinical Gastroenterology 1981,3, Supplement 2: 103-110.

21. Nagashima R, Yoshida N: Sucralfate, a basic aluminum salt of sucrose sulfate: L. Behaviors in gastroduodenal $\mathrm{pH}$. Arzneimittelforschung 1979, 29: 1668-1676.

22. Box GEP, Tiao GC: Bayesian inference in statistical analysis. Addison-Wesley, Reading, MA, 1973.

23. Goeger MP, Dupuis GK, Herndon DN, Roberson MC, Heggers JP: Antacid, sucralfate, and prostaglandin $E_{2}$ effects on the growth and potential for translocation of Pseudomonas aeruginosa, Escherichia coli, and Staphylococcus aureus in an in vitro gastric simulation. Journal of Burn Care and Rehabilitation 1991, 12; 7-12.

24. Meyers FH, Jawetz E, Goldfien A: Review of medical pharmacology. Lange Medical Publications, Los Altos, CA, 1980.

25. Nourollahi $\mathbf{M}$, Meryon SD: The antibacterial properties of four elements released from dental restorative materials. International Endodontic Journal 1989, 22: 9-16.

26. Farrah SR, Erdos GW: The production of antibacterial tubing, sutures, and bandages by in situ precipitation of metallic salts. Canadian Journal of Microbiology 1991, 37: 445-449,

27. Cornick NA, Silva $\mathbf{M}$, Gorbach SL: In vitro antibacterial activity of bismuth subsalicylate. Reviews of Infectious Diseases 1990, 12, Supplement 1: 9-10.

28. Budavari S, $\mathbf{O}^{\prime}$ Neil MJ, Smith A, Heckelman PE: The Merck index, Merck \& Co., Rahway, NJ, 1989. 